\title{
BMJ Open Influence of the day care, home and neighbourhood environment on young children's physical activity and health: protocol for the PLAYCE observational study
}

Hayley Christian, ${ }^{1,2,3}$ Clover Maitland, ${ }^{1,4}$ Stephanie Enkel, ${ }^{1}$ Georgina Trapp, ${ }^{1,2,3}$ Stewart G Trost, ${ }^{5}$ Jasper Schipperijn, ${ }^{6}$ Bryan Boruff, ${ }^{3}$ Leanne Lester, ${ }^{4}$ Michael Rosenberg, ${ }^{6}$ Stephen R Zubrick ${ }^{2,7}$

To cite: Christian $\mathrm{H}$, Maitland C, Enkel S, et al. Influence of the day care, home and neighbourhood environment on young children's physical activity and health: protocol for the PLAYCE observational study. BMJ Open 2016;6:e014058. doi:10.1136/bmjopen-2016014058

- Prepublication history for this paper is available online. To view these files please visit the journal online (http://dx.doi.org/10.1136/ bmjopen-2016-014058).

Received 27 August 2016 Revised 1 November 2016 Accepted 17 November 2016

CrossMark

For numbered affiliations see end of article.

Correspondence to Dr Hayley Christian; hayley. christian@uwa.edu.au

\section{ABSTRACT}

Introduction: The early years are a critical period in a child's health and development, yet most preschool children fail to meet physical activity guidelines. Outside of the home and neighbourhood, children spend a large proportion of time within early childhood education and care (ECEC) services such as long day care. Research is required to determine how the design of day care outdoor (and indoor) spaces provides opportunities or constraints for physical activity. A significant evidence gap surrounds what objectively measured attributes of the home and neighbourhood environment influence preschoolers' physical activity. The PLAY Spaces \& Environments for Children's Physical Activity (PLAYCE) study will empirically investigate the relative and cumulative influence of the day care, home and neighbourhood environment on preschoolers' physical activity.

Methods and analysis: The PLAYCE study is a crosssectional observational study (April 2015 to April 2018) of 2400 children aged $2-5$ years attending long day care in metropolitan Perth, Western Australia. Accelerometers will measure physical activity with indoor physical activity measured using radio frequency identification. Global positioning systems will be used to determine outdoor location of physical activity around the home and neighbourhood for a subsample $(\mathrm{n}=310)$. The day care environment will be objectively measured using a validated audit tool. Other potential individual, social and physical environmental influences on preschoolers' physical activity will be collected by geographic information systems measures, parent and day care educator surveys.

Ethics and dissemination: Ethical approval has been granted by The University of Western Australia Human Ethics Research Committee, approval number RA/4/1/ 7417. Findings will be published in international peerreviewed journals and presented at international conferences. Key findings will be disseminated to stakeholders, collaborators, policymakers and practitioners working in the ECEC sector. Day care centre directors and parents will be given a summary report of the key findings.

\section{Strengths and limitations of this study}

- The PLAY Spaces \& Environments for Children's Physical Activity (PLAYCE) study will provide a greater understanding of the combined and relative influence of the home, neighbourhood and day care environments on preschoolers' activity levels.

- This study uses a large random sample with multiple modes of data collection which will allow for a comprehensive measurement of physical activity, its geographical location and the environmental factors that influence it.

- There is a large evidence gap in regard to the optimal design features of indoor and outdoor play settings that promote preschoolers' physical activity at day care and this study will inform where best to intervene.

- The PLAYCE study is limited by its crosssectional observational design; however, findings will provide information to inform future interventions to increase preschoolers' physical activity levels across a variety of behaviour settings including early education and care policy and practice.

- Recruitment of children via day care centres will limit the generalisability of some of the findings; however, over half of all preschoolers (in Australia) usually attend formal childcare such as long day care.

\section{INTRODUCTION}

Daily physical activity is critical during the early years of life. ${ }^{1}$ Physical activity and sedentary behaviours have been shown to track from early childhood into adolescence and adulthood,,$^{2}{ }^{3}$ influencing health throughout the life course. Regular physical activity provides children with a number of health and developmental benefits, including healthy 
weight, improved bone health, cardiovascular fitness, and enhanced cognitive, emotional and psychosocial development. ${ }^{4}$ A large proportion of young children do not attain sufficient physical activity for their overall health and development ${ }^{5}$ and $\sim 20 \%$ of children aged $2-4$ are overweight or obese. ${ }^{5-8}$ There is an urgent need for quality evidence concerning the physical activity behaviour of preschoolers and the role of the environment as a barrier or facilitator of physical activity. This paper describes the study design, sample, measures and significance of the PLAY Spaces \& Environments for Children's Physical Activity (PLAYCE) study.

\section{Influence of the environment on early physical activity behaviour}

The ecological model of health considers that aspects of an individual's societal and community context can inhibit or enhance physical activity behaviour. ${ }^{9} 10$ The PLAYCE study will apply this framework to better understand the environmental influences on preschoolers' physical activity. Preschoolers spend the majority of their time either in the home, neighbourhood or within early childhood education and care (ECEC) services such as long day care, and each of these three settings influence opportunities for physical activity. ${ }^{11-14}$ There is a lack of research using an ecological approach to comprehensively examine the influence of the home, neighbourhood and day care environment on preschoolers' physical activity. The day care setting in particular is where large numbers of young children can be reached to better understand the environmental influences on physical activity.

\section{The day care environment}

In 2011, 83\% of Australian children aged 4-5 years who did not attend school were attending a preschool, or a preschool programme in an ECEC service and 54\% of 2-3 year olds usually attended formal childcare such as long day care. ${ }^{15}$ In comparison, $93 \%$ of children in the UK are enrolled in formal care ${ }^{16}$ and $26 \%$ of children under the age of 6 attend centre-based care in the US. ${ }^{17}$ ECEC services such as long day care are an important setting for increasing physical activity in the early years, yet international evidence shows that a significant proportion of preschoolers fail to meet physical activity recommendations while attending day care. ${ }^{18} 19$

The day care physical environment has the potential to either positively or negatively influence physical activity and the overall health and development of young children in care. ${ }^{14} 20-22$ A 2010 review identified that more space per child and open play areas were correlated with increased physical activity of children attending day care. ${ }^{20}$ The presence of portable play equipment has also been associated with higher preschooler physical activity. ${ }^{20} 23-27$ Further investigation into the relative value of outdoor play designs, as well as the presence and quality of individual physical environment features (eg, free space, play equipment, vegetation, paths and shade), is required to identify environmental features that best promote physical activity in the day care setting. ${ }^{27-31}$

Children also accumulate physical activity while indoors at day care. Evidence shows that preschoolers classified as highly active overall are more active indoors when compared with preschoolers classified with low levels of activity, with no differences observed outdoors. ${ }^{32}$ The indoor environment provides untapped potential for promoting and supporting physical activity, ${ }^{22}$ yet there is a large evidence gap in regard to the optimal design features that promote preschoolers' physical activity indoors.

The regulatory and operational policy frameworks of the ECEC setting have received little research attention to date. In a US study, day care centres that rated highly in eight physical activity-related policy areas had children that were more active. ${ }^{25}$ These findings highlight that day care centre policy can strongly influence the physical activity of attending preschoolers. ${ }^{20}{ }^{30}$ In a recent Australian study of 328 preschoolers, higher levels of physical activity while at day care were associated with centres having a written physical activity policy. ${ }^{33}$ Further research is required to understand the influence of the day care policy environment.

It is important that such research is conducted within existing regulatory frameworks. For example, in 2012, a new Australian National Quality Framework for Early Childhood Education and Care was implemented to provide minimum standards for day care centres which in Australia are mostly privately owned (requiring enrolment and a daily fee for service). ${ }^{34}$ The framework requires that physical activity is promoted and embedded in centre programmes, but it fails to quantify recommendations and does not specify how to promote physical activity. ${ }^{34}$ Recent data show that one-quarter of centres are not meeting the national standard for 'Health and Safety', the standard which refers to children's physical activity (Standard 2.2 : Healthy eating and physical activity are embedded in the programme for children; Element 2.2.2: Physical activity is promoted through planned and spontaneous experiences and is appropriate for each child). ${ }^{34}$ Furthermore, over a third of centres are struggling to meet the benchmark for the 'Physical Environment' national standard (Standard 3.1: The design and location of the premises is appropriate for the operation of a service; Standard 3.2: The environment is inclusive, promotes competence, independent exploration and learning through play; Standard 3.3: The service takes an active role in caring for its environment and contributes to a sustainable future). ${ }^{34}$ The 'Physical Environment' standard is the newest of the seven quality standards in the Australian National Quality Framework and lacks a clear and objective definition of what it entails and how day care centres should go about meeting it. Research is required to inform day care centres on how best to provide a physical environment that supports children's physical activity, health 
and development, thus enabling centres to meet high quality standards.

\section{The home environment}

Few studies have specifically examined the physical activity of preschoolers in the home, despite this being a behaviour setting where they spend a large proportion of time. One US study reported that $41 \%$ of preschoolers spend between 1-2 hours outside while at home. ${ }^{35}$ Thus, home-based outdoor play may be an important source of physical activity for many preschoolers. ${ }^{36-38}$ Elements of the outdoor home environment (eg, presence of yard) have been associated with increased preschoolers' physical activity ${ }^{16} 39$ and the indoor home environment (eg, electronic media) with less physical activity. ${ }^{19} 40$ Additionally, parent-level factors such as support and encouragement of children's physical activity $^{18} 41$ and participation in physical activity with children $^{42}$ are correlated with increased preschooler activity in the home. Further research into aspects of the home indoor (eg, open plan living designs) and outdoor physical environment (eg, size and attributes of the yard) that may inhibit or stimulate preschooler physical activity is needed.

\section{The neighbourhood environment}

Local neighbourhood factors can also influence preschoolers' physical activity. ${ }^{10}$ Evidence suggests that greener neighbourhoods and low levels of traffic positively influence young children's physical activity. ${ }^{10} 43$ Children who spend more time outdoors in their neighbourhood are also more likely to be physically active, ${ }^{44}$ with the likelihood of outdoor play strengthened by positive parental perceptions of neighbourhood safety. ${ }^{10} 45{ }^{46}$ Physical activity and child development are also supported by access to child-relevant destinations and services in the neighbourhood ${ }^{45} 47 \quad 48$ including local parks, recreation centres and playgrounds. ${ }^{10}$ The presence of informal play areas such as sidewalks has also been found to be positively associated with outdoor play among preschoolers. ${ }^{49}$ Overall, the findings highlight the importance of access to safe places near home for providing young children with opportunities to play outdoors and be physically active.

Many features of the neighbourhood physical environment (eg, crime-related and traffic-related safety, street connectivity, residential density, access to child-relevant destinations, quality of public open space) have not been objectively measured to determine their influence on preschoolers' activity. ${ }^{10}$ A recent review recommended population-level studies examining the role of the single, and cumulative exposures, of neighbourhood environmental features on young children's health and development. ${ }^{10}$ It is important that studies use objective measures (via geographic information systems (GIS)) of the built environment that are relevant for young children to more accurately capture and quantify the effect of the neighbourhood built environment on preschoolers' physical activity. ${ }^{50} 51$

\section{Project significance, aims and objectives}

Achieving recommended levels of physical activity for health and development is strongly influenced by the environment in which a child spends their time. Among preschoolers, time is most frequently spent in the family home, the local neighbourhood and within day care, with each of these locations either positively or negatively influencing physical activity. Further investigation into the influence of these environments is required to determine levels of preschoolers' physical activity in different behavioural settings, while identifying avenues for improvement. Additionally, there is a particular need for objective measurement of preschoolers' physical activity overall, and in the home, neighbourhood and day care centre context. To overcome limitations of previous research, ${ }^{52}$ we have used an ecological approach to comprehensively examine which physical, social and policybased attributes of the day care, home and neighbourhood environments are associated with physical activity in preschoolers aged $2-5$ years. Specifically, our objectives are to:

1. determine the physical activity levels of preschoolers while attending day care centres, and the contribution it makes towards meeting physical activity guidelines;

2. identify the features of the outdoor and indoor physical environment, policy environment and educator practices in day care centres that promote or discourage physical activity in preschoolers;

3. measure the proportion of day care centres meeting the Australian National Quality Framework for Early Childhood Education and Care 'Health and Safety' and 'Physical Environment' standards in terms of child physical activity, health and development;

4. identify the physical activity and sedentary behaviour spatial patterns of preschoolers in and around their home, local neighbourhood and at day care;

5. determine the locations in and around the home, neighbourhood and day care where preschoolers are (1) physically active and (2) physically inactive, and the attributes of these locations.

\section{METHODS}

\section{Study design}

PLAYCE is a cross-sectional observational study of $~ 2400$ preschool children, clustered by day care centre $(n=120)$. Preschool children will be recruited via day care centres so that the relative and cumulative influence of each physical activity behaviour setting (day care, home and neighbourhood) can be examined.

\section{Sampling}

Four waves of recruitment of day care centres (and their families) will occur over a 2-year period (2015-2017) to 
achieve a sample of 2400 preschoolers from 120 centres (figure 1). Based on previous studies, we expect a day care centre response rate of $\sim 50 \% .^{1153} 54$ According to the regulating body, the Australian Children's Education and Care Quality Authority (ACECQA), there are 403 eligible long day care centres located within the Metropolitan Perth and Peel Regions, Western Australia (as of September 2015). Each 6 months, we will review the number of long day care centres registered by ACECQA and add new centres to our list of centres we can sample from.

Long day care centres provide centre-based childcare by professional staff for large groups of young children. Sampling and recruitment of these centres will be based on the number of approved places (ie, maximum number of enrolling children permitted) at each centre. This proxy measure of centre size will be used to sample centres to ensure that there is maximum variability in the physical environments between centres to detect a difference in physical activity. Eligible centres will be divided into quartiles by the number of approved places. Centres in each quartile will be segmented into either low, middle or high socioeconomic status based on the Australian Bureau of Statistics Socio-Economic Index For Areas (SEIFA) ${ }^{55}$ (figure 1). Sixty centres consisting of a random sample of 10 centres from each SEIFA tertile within the lowest and highest quartiles of approved places will be approached during each of the four recruitment waves (total sample $=240$ centres). Once there are insufficient centres remaining to sample from the highest and lowest quartiles of approved places, we will sample centres from the middle quartiles choosing centres with the highest and lowest number of approved places. This sampling approach will maximise
Figure 1 PLAYCE sampling and recruitment. PLAYCE, PLAY Spaces \& Environments for Children's Physical Activity.
All long day care centres in the Perth Metropolitan and Peel Regions, Western Australia ( $N=403$ in 2015) sorted by number of approved places (i.e., size)

\begin{tabular}{|c|c|c|c|}
\hline Quartile 1 & Quartile 2 & Quartile 3 & Quartile 4 \\
\hline $\begin{array}{l}\mathrm{N}=101 \\
\text { Range: } 19-41 \text { places }\end{array}$ & $\begin{array}{c}\mathrm{N}=100 \\
\text { Range: } 42-57 \text { places }\end{array}$ & $\begin{array}{c}\quad \mathrm{N}=101 \\
\text { Range: } 58-74 \text { places }\end{array}$ & $\begin{array}{c}\mathrm{N}=101 \\
\text { Range: } 57-107 \text { places }\end{array}$ \\
\hline $\begin{array}{l}\text { Top and } \\
\text { medium }\end{array}$ & $\begin{array}{l}\text { tom quartile of centres } \\
\text { low socio-economic }\end{array}$ & $\begin{array}{l}\text { lected and sorted into } \\
\text { us (based on suburb }\end{array}$ & $\begin{array}{l}\text { tiles of high, } \\
\text { re located in) }\end{array}$ \\
\hline
\end{tabular}

\begin{tabular}{|c|c|c|}
\hline Size & $\begin{array}{c}\text { Socio-economic } \\
\text { status }\end{array}$ & $\begin{array}{c}\text { Number of childcare } \\
\text { centres }\end{array}$ \\
\hline Smallest quartile & Low & 54 \\
\hline Middle & 24 \\
\hline Largest quartile & High & 23 \\
\hline & Low & 44 \\
\hline Middle & 28 \\
\hline High & 29 \\
\hline
\end{tabular}

For each phase (1-4) of recruitment: 60 centres sampled ( 10 from each combination of size and socio-economic status)

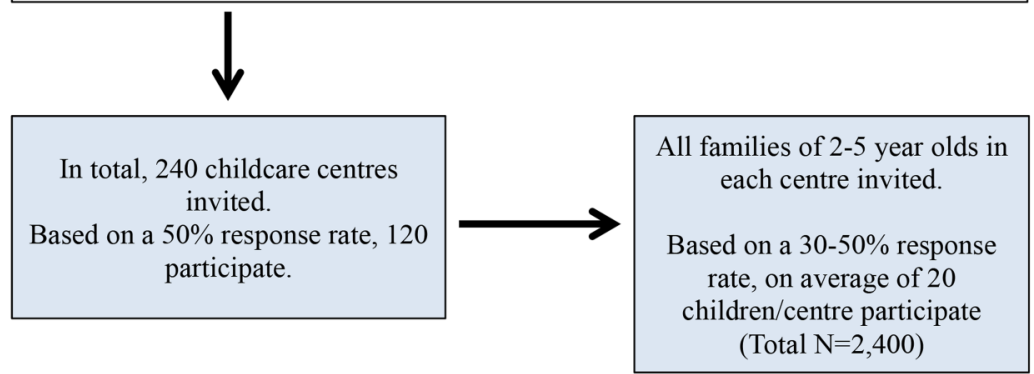


variation in size (indoor and outdoor space per child) and socioeconomic status of centres. Our sampling method is based on the assumption that larger centres have more space and this is associated with higher levels of physical activity. ${ }^{29}$

\section{Day care centre recruitment}

The PLAYCE study will use a tiered consent method, first requiring the agreement of day care centres to take part, before parents are approached. Centres will be sent an information pack about the study and the study team will follow-up with a phone call to the centre director a week later. For those centres that are part of a franchise, the consent of the managing director will be obtained before individual centres are approached. Centres that have consented to take part in the study will be briefed by the study team at a centre staff meeting. The purpose of the staff briefing will be to engage staff in the study, explain the purpose, the required involvement and methods to recruit parents and children. Centres will receive a summary report of their findings.

\section{Parent recruitment}

Recruitment of children will occur in consultation with the director of each day care centre. Parents of all children aged 2-5 years will be invited to participate, of which we expect $30-50 \%$ participation among eligible children. ${ }^{56}$ The number of participating preschoolers per day care centre is expected to range from 10 to $45 .{ }^{57}$ Children with a recognised disability (physical, emotional/behavioural or intellectual) that would affect participation in physical activity and those attending full-time formal schooling (preventing whole days spent in day care) will be ineligible for the study. Centre staff will give eligible families a recruitment pack containing information about the study, a consent form and a participant contact details form. Centres will be provided with multiple methods to let families know about the study and encourage their participation (email and newsletter templates, banners, sign up posters, flyers, etc). At the end of the study, parents will be provided with an individualised report of their child's results and children will receive a thank you gift (Frisbee).

\section{Sample size estimates}

We aim to recruit 60 day care centres from each of the largest and smallest quartile of centre size to detect a clinically significant difference in the amount of moderate-to-vigorous physical activity (MVPA) preschoolers engage in during a typical day care day. A sample of 1200 children in each of the two groups of centre size (large and small) will provide at least $80 \%$ power to detect at least an $8 \mathrm{~min}$ difference in MVPA/day between small (mean=53 min; $\mathrm{SD}=27 \mathrm{~min}$ ) and large centres (mean=61 min; $\mathrm{SD}=31 \mathrm{~min}$ ). The sample size has been inflated to account for children clustered within day care centres (clustering design effect inflation factor $=1+(m-1) \times I C C$; where $m=$ the average number of children attending each day care centre $(n=20)$ and the intraclass correlation $(\mathrm{ICC})=0.1$ ).

\section{Data collection}

Data collection will occur continuously over a 2-year period accounting for seasonal variation in weather and physical activity. Data on participating children will be collected over 7 days, and include measures of the day care centre, as well as the home and neighbourhood environment. The data collection methods used across the home, neighbourhood and day care physical activity behaviour settings are outlined in figure 2 and described in detail below.

\section{Objective measurement of preschoolers' physical activity}

ActiGraph GT3X+ accelerometers will be used to assess the frequency, duration and intensity of physical activity. The devices will be worn on an elastic belt placed at the right side of the hip. ${ }^{58}$ Children will be fitted with an accelerometer on the day the research team visits a day care centre or the next day that the child attends the centre. Accelerometers will be worn during waking hours for 7 days. Day care staff and parents will be asked to record if the accelerometer (and global positioning system (GPS) for the substudy) is removed for any reason in a diary. The devices have moderate-to-strong evidence of validity for measuring daily time spent in sedentary (SED), light (LPA), moderate (MPA) and vigorous (VPA) intensity physical activity in young children. ${ }^{58}$ Sampling intervals (epochs) will be set to $15 \mathrm{~s}$ to accommodate for the typical nature of preschoolers' physical activity. ${ }^{58}$ We will use cut-points developed by Pate and colleagues to distinguish between SED, LPA and MVPA, respectively. ${ }^{59-61}$ Data validation will be based on at least 3 weekdays (including at least 1 day at day care with $75 \%$ wear time) and 1 weekend day with a minimum 8 hours wear time/day. ${ }^{566263}$ Accelerometer data will be processed for the amount and intensity of physical activity preschoolers undertake at day care and overall. Children's height and weight will be measured.

\section{Objective measurement of preschoolers' spatial movement patterns at day care}

An RF Code radio frequency identification (RFID) system will track the location of RFID tags (worn on the wrist) in real time throughout the day care day, providing indoor room-level location information. The RFID system complements more established GPS that are unable to detect signals indoors and provides spatial location inside buildings. The RFID equipment used in this study has EC (European Conformity) and FFC (Federal Communications Commission USA) wireless regulatory certification and is designed to be worn by children or adults for personnel tracking. ${ }^{64}$ Participating children will wear an RF Code M163-i wristband tag while at day care during the study week. RFID location data will be analysed to ascertain the amount of time 


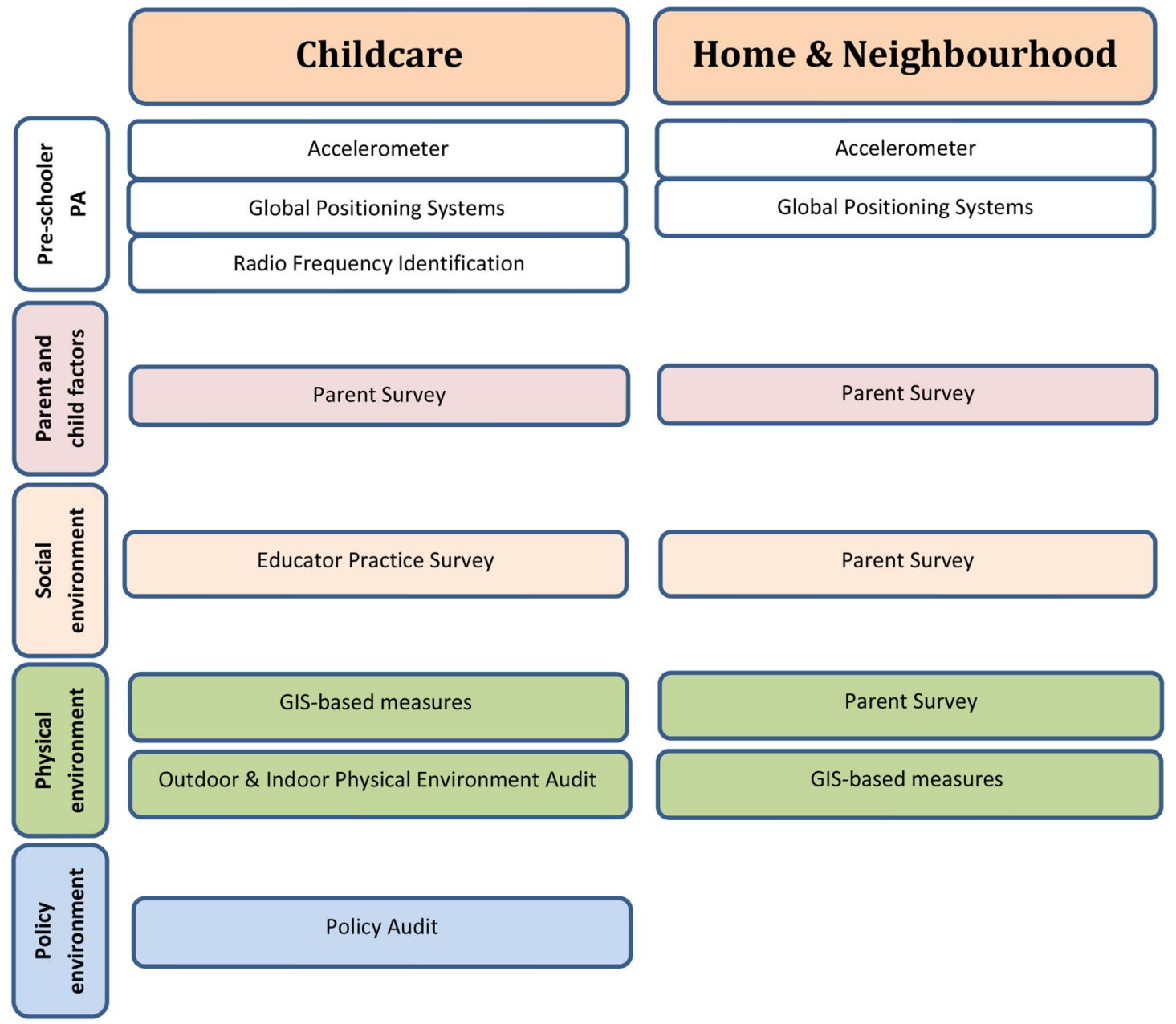

Figure 2 PLAYCE study data collection methods across preschooler physical activity behaviour settings. PLAYCE, PLAY Spaces \& Environments for Children's Physical Activity.

children spend in indoor rooms while at day care. Using the timestamp from the accelerometer and RFID tag, data will be linked so that physical activity level is matched with day care centre indoor positioning.

\section{Objective measurement of preschoolers' spatial movement} patterns at home and in the neighbourhood (GPS substudy) Qstarz Q-1000XT GPS devices will be used with a randomly selected (based on day care centre attended) subsample of children taking part in the PLAYCE study $(n=310)$ to $\log \mathrm{X}, \mathrm{Y}$ location coordinates, distance, speed, elevation and time for 7 days. This sample size will provide $80 \%$ power to detect a meaningful difference in MVPA between two groups for an attribute of the neighbourhood environment (eg, living in high vs low walkable neighbourhood). The Q-1000XT has a median dynamic accuracy of $2.9 \mathrm{~m}$ under different environmental conditions. ${ }^{65}$ The Qstarz GPS is a small device that is worn on the left hip on the same belt as the accelerometer. We aim to collect location data from the GPS unit (and corresponding accelerometer) for the majority of waking hours on at least 3 weekdays and 1 weekend day during the 7-day period. ${ }^{65}$ Outdoor location and physical activity data will be processed for analysis using the personal activity location measurement system (PALMS) software. ${ }^{65}$

\section{Measurement of the day care centre physical and policy} environment

We have adapted the Environment Assessment and Policy Observation (EPAO) Instrument ${ }^{66}$ 'Physical Environment' subscale for the Australian context and expanded it to gather detailed information on the indoor and outdoor physical environment of day care centres. The EPAO instrument was developed to assess the quality of day care centres physical activity and eating behaviours in the US ${ }^{66}{ }^{67}$ and has been validated. ${ }^{25} 68$ Physical environment and physical activity policy components of the EPAO assess fixed play equipment, portable play equipment, outdoor running space, indoor play space and whether the centre has a written policy and documented curriculum on physical activity. ${ }^{66} 69$ The presence and quality of other features of the outdoor day care physical environment including vegetation, ${ }^{70-72}$ paths ${ }^{73}$ surface material, ${ }^{28}$ slope/gradient, ${ }^{74}$ natural features ${ }^{74}$ and play settings ${ }^{66}$ will also be 
collected. Revised audit items have undergone intrarater and inter-rater reliability testing and have been found to have acceptable reliability (ie, $\kappa$ or $\mathrm{ICC}>0.60$ ).$^{75}$ Greenness will be determined by viewing satellite imagery $^{76}$ and shade above play structures examined through fisheye photography. ${ }^{71}$ The actual 'useable' outdoor and indoor space will be measured using a laser measure.

\section{Day care educator survey}

Information on educator and centre-level physical activity-related practices will be collected. Survey items are based on the Nutrition and Physical Activity Self-Assessment for Childcare ${ }^{73}$ and have been adapted for the Australian context. Time provided for physical activity, types of physical activities, equipment available for children to use, educator physical activity-related practices and professional development and the application of relevant physical activity-related policies in the centre will be measured. Items have very good to excellent test retest reliability (ie, $\kappa$ or ICC $>0.60$ ) ${ }^{75}$ Two educators per centre (centre director and one other) will complete the survey.

\section{Parent survey}

The parent survey will collect sociodemographic information about the child (eg, age, sex, siblings) and parents (eg, age, sex, socioeconomic status). Additional individual factors will include child sleep, ${ }^{77}$ temperament, ${ }^{78}$ preference for physical activity ${ }^{79}$ and physical competence. ${ }^{80}$ The social environment will be measured by parents' perceived importance and support for their child's physical activity ${ }^{82}$ and rules and limits around their child's physical activity ${ }^{56} 79$ Additional contextual measures of child physical activity behaviour will include the amount of structured and unstructured physical activity, $^{83}$ outdoor play ${ }^{36}$ and electronic media use. ${ }^{56}$ Parent perceptions of the neighbourhood environment (neighbourhood safety, crime-related safety, access to services, streets in the neighbourhood, places for walking, neighbourhood surroundings and neighbourhood preferences) will be measured using the Neighbourhood Environment Walkability Scale for Youth (NEWS-Y). ${ }^{85}$ Finally, information about home yard $\operatorname{space}^{83}$ and $\operatorname{dog}$ ownership ${ }^{86}$ will be collected.

\section{Objective measurement of day care centre and home neighbourhood built environment}

GIS data will objectively measure aspects of each day care centre, home and neighbourhood environment. Neighbourhood-level GIS measures for each centre and participant's homes will be calculated using a specified buffer area $(800 \mathrm{~m})$ from the centre/home. GIS-derived measures for day care centres and the home include outdoor space, greenness, availability and quality of public open space and traffic exposure (table 1). Home-based GIS measures also include walkability (index comprised of three subcomponents: street connectivity, land use mix and residential density ${ }^{87}$ and access to local amenities (eg, access to schools, public transport and shops and services).

\section{Data analysis plan}

In addition to descriptive statistics, a mixed model regression approach will be used to determine the amount of physical activity (LMVPA and MVPA) children accumulate while (1) at day care and the contribution it makes to meeting the recommended 3 hours of physical activity per day; and (2) while indoors and outdoors at large compared with small-sized day care centres. Analyses will also examine the influence of different combinations of indoor and outdoor space per child (eg, high amount of outdoor and indoor space/

Table 1 PLAYCE study day care centre, home and neighbourhood environment GIS-derived measures

Measure Description

Day care centre neighbourhood environment Outdoor space Area of blocks that are not covered by day care centre building (outdoor space)

Green space Access (distance) to parks, types and sizes of parks and quality (eg, playgrounds) of parks Access to nature areas Access to school grounds Neighbourhood greenness

Traffic exposure Percentage of total length of roads within a service area that are NOT main roads

Home and neighbourhood environment

Home yard area Area of residential blocks that are not covered by building (yard size)

Green space Access to parks, types and sizes of parks and quality (eg, playgrounds) of parks

Access to nature areas

Access to school grounds Neighbourhood greenness

Child-relevant Access to kindergartens, destinations child-centre-based care, child health clinics, family support services, play group venues

Street connectivity Number of 3-way or greater intersections/service area

Land use mix Access to utilitarian and recreational destinations. Evenness of spread of different land uses within a service area

Residential density Number of residential dwellings/ residential land area in service area

Low traffic Percentage of total length of roads exposure $\quad$ within a service area that are NOT main roads

Public transport Number of public transport stops stops (bus and rail) within a service area

GIS, geographic information systems; PLAYCE, PLAY Spaces \& Environments for Children's Physical Activity. 
child vs low amount of outdoor and indoor space/child) as well as features of the outdoor and indoor physical environments, policy environment and educator practices in day care centres associated with preschoolers' physical activity (and sedentary time). A moderation and mediation analysis will be performed using the physical environment quality rating for day care centres. Analyses will adjust for clustering of children within day care centres as well as individual child and parent sociodemographic factors (eg, child age and sex, time spent at day care, parent socioeconomic status).

We will determine the proportion of centres who are meeting and not meeting the 'Health and Safety' national standard in terms of achieving the recommended 3 hours of physical activity per day and the proportion of centres who are meeting and not meeting the 'Physical Environment' national standard in terms of the presence and quality of attributes within the day care physical environment. Findings from objective 2 analyses will inform what key 'Physical Environment' attributes will be included. All analyses will adjust for child-level and centre-level confounders.

Finally, we will use GPS-derived and accelerometerderived variables to determine where, when and for how long preschoolers are active (or inactive) around their home and neighbourhood. Separate multilevel models will be used to determine the influence of specific features of the home and neighbourhood environment (eg, size of backyard, access to green space, traffic exposure, neighbourhood walkability) on preschoolers' physical activity (and sedentary behaviour). Significant predictors of the home and neighbourhood environments will be placed in the one model to determine the relative significance of these environments on children's physical activity. The relative contribution of the home, neighbourhood and day care environments to achieving recommended levels of physical activity will be examined through multilevel regression models.

\section{ETHICS AND DISSEMINATION}

Directors of day care centres will provide informed written consent to participate and parents will provide informed written consent for themselves and their child's participation in the study. At the day care centre data collection visit, research staff will provide each child with a brief and simple description of the devices (accelerometers and RFID/GPS), will answer any questions the child may have and confirm they are willing to wear the device/s. All equipment to be used in the study has been approved for use with children. Furthermore, all individuals working directly with children will have a Working with Children Check as per Western Australian legislative requirements.

All participants' responses and data will be strictly confidential. No names or addresses will appear on any typed reports including publications. Only aggregated data will be used to describe research findings. All data will be retained at completion of the study for at least 7 years and kept as per The University of Western Australia requirements for data retention and disposal.

Findings will be published in international peerreviewed journals. The final report and a copy of published papers will be forwarded to key stakeholders, collaborators, policymakers and practitioners working in the ECEC sector. The research team will work closely with day care directors, educators, and the regulating body (ACECQA) to inform the Australian National Quality Framework for Early Childhood Education and Care $^{34}$ and the Australian Early Years Learning Framework. ${ }^{34}$ Findings will also be disseminated via a number of local, national and international conference presentations and invited talks. The director of each participating day care centre will receive a group summary report and individual child physical activity reports will be given to parents.

\section{DISCUSSION AND CONCLUSION}

Early physical activity behaviour has a significant effect on health across the life course. Findings from the PLAYCE study will provide important evidence for reducing the long-term effects of physical inactivity and chronic disease. The PLAYCE study will determine how much physical activity preschoolers accumulate in different behaviour settings (home, neighbourhood and day care), and the contribution each of these makes towards achieving the recommended level of physical activity for health and development. This study will investigate a range of features, including indoor and outdoor space, play equipment, the natural environment, traffic exposure, access to local amenities, day care educator practices and day care centre policies to determine their level of influence on children's physical activity across different behaviour settings. Findings will strengthen the evidence base to inform which features of the day care, home and neighbourhood physical environment are most important for influencing young children's physical activity. This information can be used by (1) early childhood educators and regulating bodies to provide day care environments that support and encourage more physical activity in preschoolers, (2) urban planners and policymakers to develop more child and family friendly neighbourhoods and (3) practitioners to develop interventions to support parents in providing opportunities for their children to play outdoors.

The findings will contribute to the evidence base required to inform policies that can positively impact preschoolers' physical activity levels across three key settings: home, day care and the neighbourhood. In seeking to influence policy and practice relating to the health and development of young children, this project will actively engage with key stakeholders, collaborators, policymakers and practitioners from the study's inception through to the dissemination and translation of findings. For example, by identifying features of the day 
care physical environment that promote physical activity and active play, we will assist childhood educators identify if their day care centre is meeting the 'Physical Environment' and 'Health and Safety' quality standards and how they can improve the physical environment to support children's physical activity, health and development. This in turn will inform practices to help centres achieve and exceed national quality standards relating to the day care environment and children's physical activity and health. Furthermore, findings from this study will be used as baseline measures for developing interventions for the day care physical (and policy) environment to establish the causal impact of the day care environment on children's physical activity and development. Considering a large proportion of preschool-age children attend day care, optimising the day care environment to facilitate young children's physical activity has the potential to increase population levels of physical activity in this age group.

\section{Author affiliations}

${ }^{1}$ School of Population Health, The University of Western Australia, Perth, Western Australia, Australia

${ }^{2}$ Telethon Kids Institute, The University of Western Australia, Perth, Western Australia, Australia

${ }^{3}$ Centre for the Built Environment and Health, School of Earth and Environment and School of Sports Science, Exercise and Health, The University of Western Australia, Perth, Western Australia, Australia ${ }^{4}$ School of Sports Science, Exercise and Health, The University of Western Australia, Perth, Western Australia, Australia

${ }^{5}$ Centre for Children's Health Research-School of Exercise and Nutrition Sciences, Queensland University of Technology, Brisbane, Queensland, Australia

${ }^{6}$ Department of Sports Science and Clinical Biomechanics, University of Southern Denmark, Odense, Denmark

${ }^{7}$ Faculty of Education, The University of Western Australia, Perth, Western Australia, Australia

Acknowledgements $\mathrm{HC}$ is supported by an Australian National Health and Medical Research Council (NHMRC)/National Heart Foundation Early Career Fellowship (\#1036350) and National Heart Foundation Future Leader Fellowship (\#100794). The WA Department of Sport and Recreation, WA Department of Local Government and Communities, WA Local Government Association, Australian Childcare Alliance, Australian Children's Education and Care Quality Authority, UWA Childcare and ArborCarbon provided in-kind support for the project. Ms Pulan Bai provided administrative assistance.

Contributors HC conceived and designed the study. CM, GT, SGT, JS, BB, LL, MR and SRZ had input to the study design. $\mathrm{HC}, \mathrm{CM}$ and SE drafted the manuscript and revised it critically at each stage. All authors contributed to the drafting of the manuscript, and read and approved the final manuscript.

Funding The PLAYCE study is supported by funding from the Western Australian (WA) Health Promotion Foundation (Healthway; \#24219).

Competing interests None declared.

Ethics approval The University of Western Australia Human Ethics Research Committee, approval number RA/4/1/7417.

Provenance and peer review Not commissioned; externally peer reviewed.

Open Access This is an Open Access article distributed in accordance with the Creative Commons Attribution Non Commercial (CC BY-NC 4.0) license, which permits others to distribute, remix, adapt, build upon this work noncommercially, and license their derivative works on different terms, provided the original work is properly cited and the use is non-commercial. See: http:// creativecommons.org/licenses/by-nc/4.0/

\section{REFERENCES}

1. Skouteris H, Dell'Aquila D, Baur LA, et al. Physical activity guidelines for preschoolers: a call for research to inform public health policy. Med J Aust 2012;196:174-6.

2. Malina R. Tracking of physical activity and physical fitness across the lifespan. Res Q Exerc Sport 1996;67:S48-57.

3. Jones RA, Hinkley T, Okely AD, et al. Tracking physical activity and sedentary behavior in childhood: a systematic review. Am J Prev Med 2013;44:651-8.

4. Timmons BW, Naylor PJ, Pfeiffer KA. Physical activity for preschool children-how much and how? Appl Physiol Nutr Metab 2007;32 (Suppl 2F)(S2E):S122-S34.

5. World Health Organisation. Prevalence of insufficient physical activity. Global health observatory (GHO) data. Geneva, Switzerland: World Health Organisation, 2015

6. Hector D, King L, Hardy L, et al. Evidence update on obesity prevention across the life-course. Sydney, Australia: Physical Activity Nutrition Obesity Research Group, 2012.

7. AlHW. A picture of Australia's children. Canberra, Australia: Australian Institute of Health and Welfare, 2009.

8. Lagstrom $\mathrm{H}$, Hakanen $\mathrm{M}$, Niinikoski $\mathrm{H}$, et al. Growth patterns and obesity development in overweight or normal-weight 13-year-old adolescents: The STRIP study. Pediatr 2008;122:e876-83.

9. Mehtala MA, Saakslahti AK, Inkinen ME, et al. A socio-ecological approach to physical activity interventions in childcare: a systematic review. Int J Behav Nutr Phys Act 2014;11:22.

10. Christian H, Zubrick SR, Foster S, et al. The influence of the neighborhood physical environment on early child health and development: a review and call for research. Health Place 2015;33:25-36.

11. Van Cauwenberghe $\mathrm{E}$, Jones RA, Hinkley $\mathrm{T}$, et al. Patterns of physical activity and sedentary behaviour in preschool children. Int $J$ Behav Nutr Phys Act 2012;9:138.

12. Vale S, Silva $P$, Santos $R$, et al. Compliance with physical activity guidelines in preschool children. J Sports Sci 2010;28:603-8.

13. Pate RR, Mclver K, Dowda M, et al. Directly observed physical activity levels in preschool children. J Sch Health 2008;78:438-44.

14. Hodges EA, Smith C, Tidwell S, et al. Promoting physical activity in preschoolers to prevent obesity: a review of the literature. $J$ Pediatr Nurs 2013;28:3-19.

15. Australian Bureau Statistics. Childhood education and care Australia Canberra, Australia: Australian Bureau of Statistics, 2011

16. Janta B. Caring for children in Europe: How childcare, parental leave and flexible working arrangements interact in Europe. Report prepared for the European Commission, Directorate-General for Employment, Social Affairs and Inclusion. RAND Corporation, Europe, 2014.

17. Child Care Aware of America. Child care in America. Virginia, USA Child Care Aware of America, 2012.

18. Tucker P. The physical activity levels of preschool-aged children: a systematic review. Early Child Res Q 2008:23:547-58.

19. Reilly JJ. Low levels of objectively measured physical activity in preschoolers in child care. Med Sci Sports Exerc 2010;42:502-7.

20. Trost SG, Ward DS, Senso M. Effects of child care policy and environment on physical activity. Med Sci Sports Exerc 2010;42:520-5.

21. Timmons BW, LeBlanc AG, Carson V, et al. Systematic review of physical activity and health in the early years (aged 0-4 years). Appl Physiol Nutr Metab 2012;37:773-92.

22. Vanderloo LM, Tucker $P$, Johnson AM, et al. The influence of centre-based childcare on preschoolers' physical activity levels: a cross-sectional study. Int J Environ Res Public Health 2014;11:1794-802.

23. Brown WH, Pfeiffer KA, Mclver KL, et al. Social and environmental factors associated with preschoolers' nonsedentary physical activity. Child Dev 2009;80:45-58.

24. Hannon JC, Brown BB. Increasing preschoolers' physical activity intensities: an activity-friendly preschool playground intervention. Prev Med 2008;46:532-6.

25. Bower JK, Hales DP, Tate DF, et al. The childcare environment and children's physical activity. Am J Prev Med 2008;34:23.

26. Dowda M, Brown WH, Mclver KL, et al. Policies and characteristics of the preschool environment and physical activity of young children Pediatr 2009;123:e261-e66.

27. Gubbels JS, Van Kann DH, Jansen MW. Play equipment, physical activity opportunities, and children's activity levels at childcare. $J$ Environ Public Health 2012;2012;326520.

28. Cosco NG, Moore RC, Islam MZ. Behavior mapping: a method for linking preschool physical activity and outdoor design. Med Sci Sports Exerc 2010;42:513-9. 
29. Trost S, Ward DS, Senso M. Effects of childcare policy and environment on physical activity. Med Sci Sports Exerc 2010;42:520-5.

30. Hinkley T, Carson V, Hesketh KD. Physical environments, policies and practices for physical activity and screen-based sedentary behaviour among preschoolers within child care centres in Melbourne, Australia and Kingston, Canada. Child Care Health Dev 2015;41:132-8.

31. Cosco NG, Moore RC, Smith WR. Childcare outdoor renovation as a built environment health promotion strategy: Evaluating the preventing obesity by design intervention. Am J Health Promot 2014;28:S27-32.

32. Howie EK, Brown WH, Dowda M, et al. Physical activity behaviours of highly active preschoolers. Pediatr Obes 2013;8:142-9.

33. Bell AC, Finch $M$, Wolfenden $L$, et al. Child physical activity levels and associations with modifiable characteristics in centre-based childcare. Aust N Z J Public Health 2015;39:232-6.

34. Australian Children's Education \& Care Quality Authority. Guide to the National Quality Standard. Australian Government, 2011.

35. Marino AJ, Fletcher EN, Whitaker RC, et al. Amount and environmental predictors of outdoor playtime at home and school: a cross-sectional analysis of a national sample of preschool-aged children attending Head Start. Health Place 2012;18:1224-30.

36. Burdette HL, Whitaker RC. A national study of neighborhood safety, outdoor play, television viewing, and obesity in preschool children. Pediatr 2005;116:657-62.

37. Hüttenmoser M. Children and their living surroundings: empirical investigations into the significance of living surroundings for the everyday life and development of children. Child Environ 1995;12:403-13.

38. Aarts MJ, Wendel-Vos W, van Oers HA, et al. Environmental determinants of outdoor play in children: a large-scale cross-sectional study. Am J Prev Med 2010;39:212-19.

39. Barnett L, Hinkley T, Okely AD, et al. Child, family and environmental correlates of children's motor skill proficiency. Med Sci Sports Exerc 2012;16:332-6.

40. Sugiyama T, Okely AD, Masters JM, et al. Attributes of child care centers and outdoor play areas associated with preschoolers' physical activity and sedentary behavior. Environ Behav 2012;44:334-49.

41. Yao CA, Rhodes RE. Parental correlates in child and adolescent physical activity: a meta-analysis. Int J Behav Nutr Phys Act 2015;12:10

42. Dwyer GM, Higgs J, Hardy LL, et al. What do parents and preschool staff tell us about young children's physical activity: a qualitative study. Int J Behav Nutr Phys Act 2008;5:66.

43. Corder K, Sallis JF, Crespo NC, et al. Active children use more locations for physical activity. Health Place 2011;17:911-19.

44. Pate RR, Pfeiffer KA, Trost SG, et al. Physical activity among children attending preschools. Pediatr 2004;114:1258-63.

45. Kenney MK. Child, family, and neighborhood associations with parent and peer interactive play during early childhood. Matern Child Health J 2012;16 Suppl 1:S88-S101.

46. Carver A, Timperio A, Crawford D. Playing it safe: The influence of neighbourhood safety on children's physical activity-A review. Health Place 2008;14:217-27.

47. Rosenberg L, Jarus $\mathrm{T}$, Bart O, et al. Can personal and environmental factors explain dimensions of child participation? Child Care Health Dev 2011;37:266-75.

48. Fan $\mathrm{Y}$, Chen $\mathrm{Q}$. Family functioning as a mediator between neighborhood conditions and children's health: Evidence from a national survey in the United States. Soc Sci Med 2012;74:1939-47.

49. Aarts MJ, deVries SI, vanOers HA, et al. Outdoor play among children in relation to neighborhood characteristics: a cross-sectional neighbourhood observation study. Int J Behav Nutr Phys Act 2012;9:98-109.

50. Giles-Corti B, Salmon J. Encouraging children and adolescents to be more active. BMJ 2007;335:677-8.

51. Giles-Corti B, Timperio A, Bull F, et al. Understanding physical activity environmental correlates: increased specificity for ecological models. Exerc Sport Sci Rev 2005;33:175-81.

52. Gubbels JS, Van Kann DHH, de Vries NK, et al. The next step in health behavior research: The need for ecological moderation analyses - an application to diet and physical activity at childcare. Int $J$ Behav Nutr Phys Act 2014;11:52.

53. Hinkley $T$, Salmon J, Okely AD, et al. Correlates of preschoo children's physical activity. Am J Prev Med 2012;43:159-67.

54. Jones H, Jones E, Bailey R. Preschoolers' physical Activity: role of the Childcare Setting and the Built Environment. The University of Western Australia, 2014
55. Australian Bureau of Statistics. Information paper: an introduction to socio-economic indexes for areas (SEIFA). Canberra, Australia: Australian Government, 2008

56. Hinkley T, O'Connell E, Okely AD, et al. Assessing volume of accelerometry data for reliability in preschool children. Med Sci Sports Exerc 2012;44:2436-41.

57. Australian Children's Education \& Care Quality Authority. Education and Care Services National Law and Education and Care Services National Regulations. Australian Government, 2013.

58. Pate RR, O'Neill JR, Mitchell J. Measurement of physical activity in preschool children. Med Sci Sports Exerc 2010;42:508-12.

59. Janssen X, Cliff DP, Reilly JJ, et al. Predictive validity and classification accuracy of ActiGraph energy expenditure equations and cut-points in young children. PLOS ONE 2013;8:e79124.

60. Goldfield GS, Harvey A, Grattan K, et al. Physical activity promotion in the preschool years: a critical period to intervene. Int $J$ Environ Res Public Health 2012;9:1326-42.

61. Pate RR, Almeida MJ, Mclver KL, et al. Validation and calibration of an accelerometer in preschool children. Obesity (Silver Spring) 2006;14:2000-6.

62. Hnatiuk JA, Salmon J, Hinkley T, et al. A review of preschool children's physical activity and sedentary time using objective measures. Am J Prev Med 2014:47:487-97.

63. Rice KR, Trost SG. Physical activity levels among children attending family day care. J Nutr Educ Behav 2014;46:197-202.

64. RF Code Inc. RF Code Active RFID Tags: Features, Specifications, and Deployment Guidelines, RF Code Inc, Austin, TX, USA, 2014.

65. Jankowska MM, Schipperijn J, Kerr J. A framework for using GPS data in physical activity and sedentary behavior studies. Exerc Sport Sci Rev 2015;43:48-56.

66. Ball S, Benjamin S, Hales D, et al. The Environment and Policy Assessment and Observation (EPAO) child care nutrition and physical activity instrument. Chapel Hill, NC, USA: Center for Health Promotion and Disease Prevention, University of North Carolina, 2005.

67. Ward D, Hales D, Haverly K, et al. An instrument to assess the obesogenic environment of child care centers. Am J Health Behav 2008;32:380-6.

68. Ward DS, Benjamin SE, Ammerman AS, et al. Nutrition and physica activity in child care: results from an environmental intervention. Am J Prev Med 2008:35:352-6.

69. Gubbels JS, Kremers SPJ, van Kann DHH, et al. Interaction between physical environment, social environment, and child characteristics in determining physical activity at child care. Health Psychol 2011;30:84-90.

70. Boldemann C, Blennow M, Dal $\mathrm{H}$, et al. Impact of preschool environment upon children's physical activity and sun exposure. Prev Med 2006;42:301-8.

71. Mårtensson F, Boldemann C, Söderström M, et al. Outdoor environmental assessment of attention promoting settings for preschool children. Health Place 2009;15:1149-5.

72. Boldemann $\mathrm{C}, \mathrm{Dal} \mathrm{H}$, Mårtensson $\mathrm{F}$, et al. Preschool outdoor play environment May combine promotion of children's physical activity and sun protection. Further evidence from Southern Sweden and North Carolina. Sci Sports 2011;26:72-82.

73. Ward D, Morris E, McWilliams C, et al. Go NAP SACC: Nutrition and Physical Activity Self-Assessment for Child Care. 2nd edn. Center for Health Promotion and Disease Prevention and Department of Nutrition; University of North Carolina at Chapel Hill, University of North Carolina at Chapel Hill, 2014.

74. Little $\mathrm{H}$, Sweller N. Affordances for risk-taking and physical activity in Australian early childhood education settings. Early Childhood Educ J 2015;43:337-45.

75. Landis JR, Koch GG. The measurement of observer agreement for categorical data. Biometrics 1977;33:159-74.

76. Pereira G, Christian H, Foster S, et al. The association between neighborhood greenness and weight status: An observational study in Perth Western Australia. Environ Health 2013:12:1-12.

77. Australian Government Department of Social Services. Growing Up in Australia: The Longitudinal Study of Australian Children Survey. Australia Government, 2005.

78. Goodman A, Goodman R. Strengths and difficulties questionnaire as a dimensional measure of child mental health. J Am Acad Child Adolesc Psychiatry 2009;48:400-3.

79. Vaughn AE, Hales D, Ward DS. Measuring the physical activity practices used by parents of preschool children. Med Sci Sports Exerc 2013;45:2369-77.

80. Southall JE, Steele JR, Okely AD. Actual and perceived physical competence in overweight and nonoverweight children. Pediatr Exerc Sci 2004;16:15-24

81. Trost SG, Sallis JF, Pate RR, et al. Evaluating a model of parental influence on youth physical activity. Am J Prev Med 2003;25:277-82. 
82. Sallis JF, Taylor WC, Dowda M, et al. Correlates of vigorous physical activity for children in grades 1 through 12: comparing parent-reported and objectively measured physical activity. Pediatr Exerc Sci 2002;14:30.

83. Hinkley T, Salmon J, Okely AD, et al. The HAPPY Study: Development and reliability of a parent survey to assess correlates of preschool children's physical activity. J Sci Med Sport 2012;15:407-17.

84. Burdette HL, Whitaker RC, Daniels SR. Parental report of outdoor playtime as a measure of physical activity in preschool-aged children. Arch Pediatr Adolesc Med 2004;158:353.
85. Rosenberg D, Ding D, Sallis JF, et al. Neighborhood Environment Walkability Scale for Youth (NEWS-Y): Reliability and relationship with physical activity. Prev Med 2009;49:213-18.

86. Cutt H, Giles-Corti B, Knuiman M. Dogs And Physical Activity (D.A. P.A.) Tool. Perth: School of Population Health, The University of Western Australia, 2004.

87. Christian HE, Bull FC, Middleton NJ, et al. How important is the land use mix measure in understanding walking behaviour? Results from the RESIDE study. Int J Behav Nutr Phys Act 2011;8:1-12. 